\title{
Defining the mycoplasma 'cytoskeleton': the protein composition of the Triton X-100 insoluble fraction of the bacterium Mycoplasma pneumoniae determined by 2-D gel electrophoresis and mass spectrometry
}

\author{
J. T. Regula, ${ }^{1}$ G. Boguth, ${ }^{2}$ A. Görg, ${ }^{2}$ J. Hegermann, ${ }^{3}$ F. Mayer, ${ }^{3}$ R. Frank ${ }^{1} \dagger$ \\ and R. Herrmann ${ }^{1}$
} Author for correspondence: R. Herrmann. Tel: +49 6221 546827. Fax: +496221 545893.
e-mail: r.herrmann@mail.zmbh.uni-heidelberg.de

1 Zentrum für molekulare Biologie Heidelberg (ZMBH) Mikrobiologie, Universität Heidelberg, Im Neuenheimer Feld 282, D-69120 Heidelberg, Germany

2 Technische Universität München, Institut für Lebensmitteltechnologie und Analytische Chemie, Germany

3 Institut für Mikrobiologie und Genetik, GeorgAugust-Universität Göttingen, Germany

\begin{abstract}
After treating Mycoplasma pneumoniae cells with the nonionic detergent Triton X-100, an undefined, structured protein complex remains that is called the 'Triton X-100 insoluble fraction' or 'Triton shell'. By analogy with eukaryotic cells and supported by ultrastructural analyses it is supposed that this fraction contains the components of a bacterial cytoskeleton-like structure. In this study, the composition of the Triton X-100 insoluble fraction was defined by electron microscopic screening for possible structural elements, and by two-dimensional (2-D) gel electrophoresis and MS to identify the proteins present. Silver staining of 2-D gels revealed about 100 protein spots. By staining with colloidal Coomassie blue, about 50 protein spots were visualized, of which 41 were identified by determining the mass and partial sequence of tryptic peptides of individual proteins. The identified proteins belonged to several functional categories, mainly energy metabolism, translation and heat-shock response. In addition, lipoproteins were found and most of the proteins involved in cytadherence that were previously shown to be components of the Triton X-100 insoluble fraction. There were also 11 functionally unassigned proteins. Based on sequence-derived predictions, some of these might be potential candidates for structural components.

Quantitatively, the most prevalent proteins were the heat-shock protein DnaK, elongation factor Tu and subunits $\alpha$ and $\beta$ of the pyruvate dehydrogenase complex (PdhA, PdhB), but definite conclusions regarding the composition of the observed structures can only be drawn after specific proteins are assigned to them, for example by immunocytochemistry.
\end{abstract}

Keywords: wall-less bacteria, protein identification, electron microscopy, Triton $\mathrm{X}-100$ insoluble proteins

\section{INTRODUCTION}

Mycoplasma pneumoniae is one of the smallest bacteria known, with a genome of only $816 \mathrm{kbp}$ (Himmelreich et al., 1996) that most probably evolved by reduction from the larger genomes of Gram-positive bacteria (Razin et

\footnotetext{
†Present address: GAG Bioscience AG, Bremen, Germany.
}

Abbreviations: 1-D, one-dimensional; 2-D, two-dimensional; IPG, immobilized $\mathrm{pH}$ gradient. al., 1998; Weisburg et al., 1989). M. pneumoniae lacks a cell wall and in nature is always associated with a host cell. Its dependence on a parasitic lifestyle can be attributed to the loss of genetic information for the synthesis of essential compounds, as shown by biochemical studies (Pollack et al., 1997), the annotation of the complete genome sequence (Himmelreich et al., 1996) and a recent re-annotation (Dandekar et al., 2000). However, M. pneumoniae can be grown in vitro without host cells in a medium containing serum.

Over the past 20 years, indications have accumulated 
that M. pneumoniae possesses a cytoskeleton-like structure, probably as a substitute for the missing cell wall (Biberfeld \& Biberfeld, 1970; Göbel et al., 1981; Krause, 1996; Krause et al., 1982; Meng \& Pfister, 1980; Wilson \& Collier, 1976). By analogy with eukaryotic cells, such a cytoskeleton could provide the necessary framework for maintaining and stabilizing the shape of M. pneumoniae (Trachtenberg, 1998), for motility (Radestock \& Bredt, 1977) and for the formation of an asymmetric cell. Cell asymmetry is related to the attachment organelle, a membrane-bound extension of the cell. The correct assembly of this organelle is a prerequisite for binding of $M$. pneumoniae to specific receptors on the host cell (Krause, 1996; Razin \& Jacobs, 1992). Among the proteins known to be present in an intact attachment organelle are the proposed adhesin proteins $\mathrm{P} 1$ ( $\mathrm{Hu}$ et al., 1977; Inamine et al., 1988; Krause, 1996; Su et al., 1987) and P30 (Dallo et al., 1990; Romero-Arroyo et al., 1999), and a number of other proteins including P40 and P90, cleavage products derived from the ORF6 gene of the P1 operon (Inamine et al., 1988; Layh-Schmitt \& Harkenthal, 1999; Sperker et al., 1991), and HMW3 (Ogle et al., 1991; Stevens \& Krause, 1992). Lack of any one of these proteins results in an adherence-negative phenotype. The hypothesis is that in adherence-negative strains the putative cytoskeleton-like structure is lacking, malfunctioning or absent. A more detailed review of this topic has been published recently (Krause, 1996).

The first experimental indication of a cytoskeleton-like structure in M. pneumoniae was provided by Meng \& Pfister (1980) who detected by electron microscopy rodlike condensed structures localized in the attachment organelle and thin fibrous structures extending into the cell body. These observations were confirmed by other researchers (Göbel et al., 1981). In these experiments, M. pneumoniae cells grown on cover slips were treated with $1 \%$ Triton $\mathrm{X}-100$ and the remaining proteins were stained with uranyl acetate for electron microscopy. In most pictures, a rod-like condensation, also called the tip structure, with a terminal button and a basal node was visible (Göbel et al., 1981; Meng \& Pfister, 1980). This rod-like condensation has alternating electronlucent and -opaque rings (Meng \& Pfister, 1980). This structure is sometimes still surrounded by membrane fragments and has some filamentous extensions attached (Göbel et al., 1981; Meng \& Pfister, 1980). These experiments, and studies on the architecture and composition of eukaryotic cytoskeletons from many different cells (Herrmann \& Wiche, 1983; Starger \& Goldman, 1977; Steinert et al., 1978) that have been treated with the detergent Triton X-100, suggested that a cytoskeleton-like structure could also be concentrated in a Triton X-100 insoluble fraction of M. pneumoniae. About 30 proteins could be visualized by SDS-PAGE of the Triton X-100 insoluble fraction and staining with Coomassie blue (Krause, 1996). The correlation between the adhesion organelle and cytadherence was shown in several studies (Krause et al., 1997; Romero-Arroyo et al., 1999) by isolating spontaneous mutants with a cytadherence-negative phenotype that possessed the adhesins P1 and P30 but had lost the high-molecularmass proteins HMW1, HMW2 and HMW3 (Krause et al., 1982; Layh-Schmitt et al., 1995). Cytadherencepositive revertants had regained the HMW proteins (Krause et al., 1997), reinforcing their correlation with cytadherence.

HMW1 (Dirksen et al., 1996) and HMW3 (Ogle et al., 1991) show an unusual amino acid composition with an extended acidic, proline-rich domain. HMW2 was predicted to have the potential for the formation of an extended coiled-coil structure (Krause et al., 1997). In another approach, a protein expression library was constructed by fusing randomly fragmented M. pneumoniae DNA to the dihydrofolate reductase gene (Proft \& Herrmann, 1994). Screening of this expression library with an antiserum directed against the Triton X-100 insoluble fraction of $M$. pneumoniae led to the discovery of the proteins P65 (Proft et al., 1995) and P200 (Proft et al., 1996). These proteins were candidates for structural proteins based upon their predicted features. Like HMW1 and HMW3, they have an acidic, proline-rich domain. Furthermore, P65 and P200, like HMW2, HMW1 and HMW3, accumulate in the Triton X-100 insoluble fraction. But none of these proteins, or any other of the predicted 688 ORFs (Dandekar et al., 2000), has a significant sequence similarity to a known cytoskeleton protein. This is not surprising, as structural components may not be conserved at the sequence level even though the proteins have similar structural features. For instance the proteins HMW1-3 show only 50-60\% amino acid sequence identity with the corresponding proteins in Mycoplasma genitalium, which is the closest known relative to $M$. pneumoniae. This value is low compared to the $75-95 \%$ identity for standard housekeeping genes (Herrmann \& Reiner, 1998; Himmelreich et al., 1997); however the sequence similarities to the orthologous structural proteins in phylogenetically more distantly related species would probably be too low to be significant. To better characterize this fraction and to identify new structural components of the cytoskeletonlike structure, we decided to determine the protein composition of the Triton X-100 insoluble fraction of M. pneumoniae. Since the complete sequence of the genome is known (Himmelreich et al., 1996), twodimensional (2-D) gel electrophoresis combined with MS was the method of choice for this analysis (Eng et al., 1994; Fountoulakis et al., 1998; Görg et al., 1998, 1999; Shevchenko et al., 1996; Wasinger et al., 1995, 2000; Wilkins et al., 1996). Sensitivity and throughput of protein analyses were significantly enhanced by the use of mass spectrometric methods. Essentially any protein visible on a gel and listed in the sequence database can be identified by mass spectrometric analysis of peptides generated by in-gel digestion of the protein. To identify a protein, the sequence-specific peptide fragment patterns created by the mass spectrometer are correlated with the database using dedicated computer programs (Eng et al., 1994; Shevchenko et al., 1996). The high information content of the mass spectrometric fragment patterns allows protein identity to be established auto- 
matically and without operator interpretation (Eng et al., 1994).

\section{METHODS}

Cell fractionation. M. pneumoniae cells were grown for $96 \mathrm{~h}$ in modified Hayflick medium at $37^{\circ} \mathrm{C}$ in $150 \mathrm{~cm}^{2}$ tissue culture flasks. For cell fractionation, the adherent bacteria were washed twice with PBS $(150 \mathrm{mM} \mathrm{NaCl}, 10 \mathrm{mM}$ $\mathrm{Na}_{2} \mathrm{HPO}_{4}, \mathrm{pH} 7 \cdot 4$ ) at room temperature and then treated in the flask with the following two buffers (Herrmann \& Wiche, 1983): lysis buffer low, containing $0.5 \times$ PBS, $50 \mathrm{mM}$ MOPS pH 6.8, $1 \mathrm{mM}$ EGTA [ethylene glycol-bis $(\beta$-aminoethyl ether)], $10 \mathrm{mM} \mathrm{MgCl}, 0 \cdot 2 \%$ (v/v) Triton X-100 and $1 \mathrm{mM}$ PMSF; and lysis buffer high, containing $0.5 \times \mathrm{PBS}, 50 \mathrm{mM}$ MOPS pH 6.8, $10 \mathrm{mM} \mathrm{MgCl}_{2}, 1 \%$ Triton X-100, $0.05 \mathrm{mg}$ DNase $\mathrm{ml}^{-1}$ and $1 \mathrm{mM}$ PMSF. Cells were incubated with $2 \mathrm{ml}$ lysis buffer low for $2 \mathrm{~min}$ at room temperature; the supernatant (S1; Fig. 1) was then carefully removed, and the cells put on ice and incubated with $2 \mathrm{ml}$ lysis buffer high for $3 \mathrm{~min}$ with gentle agitation (Fig. 1). After $3 \mathrm{~min}, 0.5 \mathrm{ml} 5 \mathrm{M} \mathrm{NaCl}$ was added and incubation continued for $3 \mathrm{~min}$ on ice. This treatment detached cell fragments from the plastic surface. Cell fragments still adhering to the plastic surface were scratched off. The suspensions were combined (S2), centrifuged for $10 \mathrm{~min}$ at $14000 \mathrm{~g}$ in an Eppendorf 5402 centrifuge at $4{ }^{\circ} \mathrm{C}$ and separated into a pellet, P4, and supernatant, S5. P4 contained the Triton X-100 insoluble fraction that was used for further analysis. Supernatant S1 was treated as for S2 and the resulting pellet, $\mathrm{P} 2$, and supernatant, S3, stored at $-20{ }^{\circ} \mathrm{C}$.

2-D electrophoresis. Equipment and chemicals used for 2-D gel electrophoresis and MS have been described recently

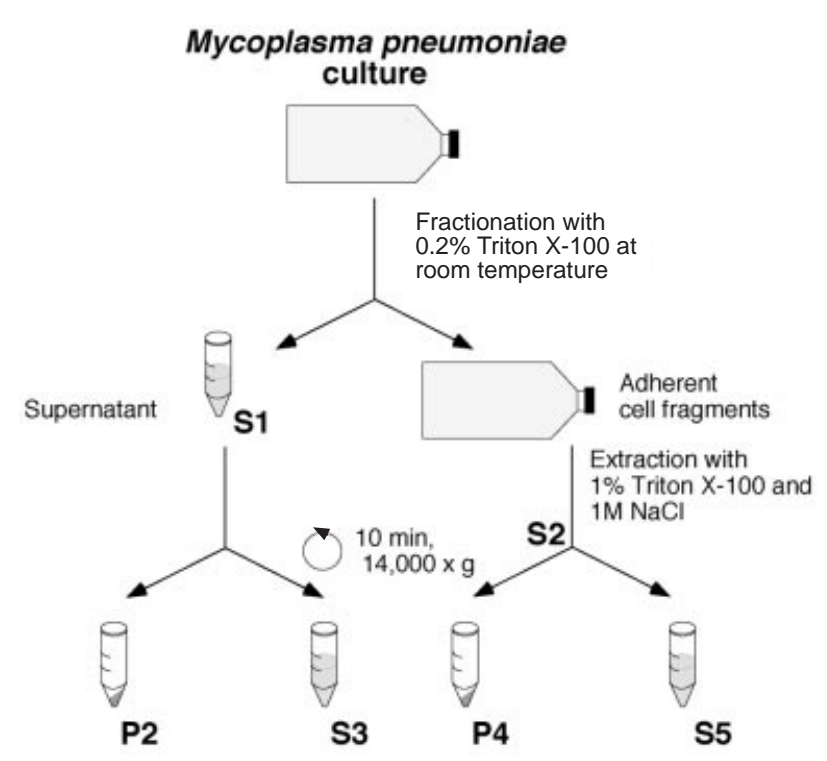

Fig. 1. Schematic representation of Triton $X-100$ fractionation. M. pneumoniae cells were fractionated with $0.2 \%$ Triton X-100 as described in Methods. The supernatant (S1) was removed from the adherent cell fragments, which were further extracted with $1 \%$ Triton $\mathrm{X}-100$ and $1 \mathrm{M} \mathrm{NaCl}$. This suspension, and also the $S 1$ fraction, were centrifuged and separated into supernatants S3 and S5 and pellets P2 and P4 to yield four subcellular fractions. Fraction P4 was the Triton X-100 insoluble fraction.
(Regula et al., 2000). 2-D electrophoresis (IPG-Dalt) was done with immobilized $\mathrm{pH}$ gradients according to Görg et al. (1988) with minor modifications (Regula et al., 2000). For details see http://www.weihenstephan.de/blm/deg.

In-gel digestion and liquid chromatography-MS analysis. The methods used for protein identification were recently described by Regula et al. (2000).

Triton X-100 treatment of cells grown on electron microscope grids. M. pneumoniae cells were grown on Formvar carboncoated nickel grids. For growth, each well of a 24-well cell culture plate was filled with $1 \mathrm{ml}$ mycoplasma medium containing mycoplasma cells, and one grid per well was placed, with the support film facing upwards, into the medium. Incubation was for $3 \mathrm{~d}$ at $37^{\circ} \mathrm{C}$. The medium was removed and replaced by $1 \mathrm{ml}$ PBS per well, and all grids were then washed twice with PBS at room temperature in their respective wells. The washing solution was removed and replaced by $1 \mathrm{ml}$ per well of a solution containing $20 \mathrm{mM}$ Tris $/ \mathrm{HCl}$, $150 \mathrm{mM} \mathrm{NaCl}$ and 2\% Triton X-100 (Stevens \& Krause, 1991). After $30 \mathrm{~min}$ incubation at $37^{\circ} \mathrm{C}$, the Triton solution was removed and the grids were washed twice with PBS at room temperature in their respective wells. Finally, the samples were fixed in an aqueous solution of $0 \cdot 2 \%(\mathrm{v} / \mathrm{v})$ glutaraldehyde and $0.2 \%(\mathrm{v} / \mathrm{v})$ formaldehyde at room temperature for $10 \mathrm{~s}$ and air-dried.

Cryoultramicrotomy. M. pneumoniae cells were washed twice in $50 \mathrm{mM} \mathrm{PBS}$ and then fixed in $0.3 \%$ formaldehyde and $0.3 \%$ glutaraldehyde in PBS for $10 \mathrm{~min}$ at $4{ }^{\circ} \mathrm{C}$. Afterwards, the cells were centrifuged at $6000 \mathrm{~g}$ for $5 \mathrm{~min}$ and resuspended in $1 \mathrm{ml}$ of $10 \%(\mathrm{w} / \mathrm{v})$ gelatin at $37^{\circ} \mathrm{C}$. The gelatin was poured into a Petri dish to form a $1 \mathrm{~mm}$ thick layer and cooled to $0^{\circ} \mathrm{C}$. The solidified gelatin was covered with a solution of $0.3 \%$ formaldehyde and $0.3 \%$ glutaraldehyde in PBS for $30 \mathrm{~min}$ at $0{ }^{\circ} \mathrm{C}$, washed with PBS and cut into $1 \mathrm{~mm}^{3}$ cubes. These were incubated for $12 \mathrm{~h}$ at $2{ }^{\circ} \mathrm{C}$ in a mixture containing $1.6 \mathrm{M}$ sucrose in $0.4 \mathrm{M} \mathrm{NaPO}_{4}$ buffer and $25 \%$ polyvinylpyrrolidone (Griffiths et al., 1984). Afterwards they were mounted on a pin with $2 \cdot 3 \mathrm{M}$ sucrose as a 'glue' and frozen in liquid nitrogen. Ultrathin sections $50 \mathrm{~nm}$ thick were cut at $-85^{\circ} \mathrm{C}\left(-100^{\circ} \mathrm{C}\right.$ knife temperature) on a cryoultramicrotome FC4 (ReichertJung). Cryosections were removed from the knife with a drop of 2.3 $\mathrm{M}$ sucrose in a wire loop and transferred onto Formvar carbon-coated nickel grids. The grids were then floated on distilled water for $5 \mathrm{~min}$, with the specimen facing downwards, and blotted dry on filter paper.

Triton X-100 treatment of cells grown in culture flasks and preparation for electron microscopy. M. pneumoniae cells were cultured and fractionated with Triton X-100 and $\mathrm{NaCl}$ as described above. For preparation for electron microscopy, glutaraldehyde and formaldehyde were added to fraction P4 (Fig. 1), to a final concentration of $0 \cdot 2 \%$ each. Triton shells were transferred to Formvar carbon-coated grids by floating grids, one per $40 \mu \mathrm{l}$ drop, with the support film facing towards the drop surface, for $30 \mathrm{~s}$ on the drop. Afterwards, the grids were blotted dry on filter paper and air-dried.

Electron microscopy. Each grid was stained by floating it, for $1 \mathrm{~s}$, on the surface of a $40 \mu \mathrm{l}$ drop of $3 \%$ neutralized phosphotungstic acid (PTA). Afterwards, the grids were removed from the drop, most of the PTA was removed from the grid with filter paper and the grid was air-dried. Electron microscopy of the samples was done with a Philips EM 301 transmission electron microscope operated in the bright field mode at $80 \mathrm{kV}$.

Western blotting. Western blotting of one-dimensional (1-D) 
Table 1. Proteins of the Triton $X-100$ insoluble fraction

\begin{tabular}{|c|c|c|c|c|c|c|}
\hline \multirow[t]{2}{*}{ Gene no.* } & \multirow[t]{2}{*}{ MPN no $†$} & \multirow[t]{2}{*}{ ORF name $\ddagger$} & \multirow{2}{*}{$\begin{array}{l}\text { Proposed function/annotation (gene name) } \\
\text { and orthologous gene in } M . \text { genitalium (MG) }\end{array}$} & \multicolumn{3}{|c|}{ Structural features $₫$} \\
\hline & & & & $\mathrm{TM}$ & $\mathrm{C}-\mathrm{C}$ & PR \\
\hline \multicolumn{7}{|c|}{ Energy metabolism } \\
\hline 73 & 082 & R02_orf648 & Transketolase 1 (TklB), MG66 & 3 & - & - \\
\hline 129 & 025 & B01_orf288 & Fructose-bisphosphate aldolase (Tsr), MG23 & - & - & - \\
\hline 168 & 674 & K05_orf312 & L-Lactate dehydrogenase (Ldh), MG460 & 1 & - & - \\
\hline 244 & 598 & D02_orf475 & ATP synthase beta chain (AtpD), MG399 & - & - & - \\
\hline 314 & 528 & G12_orf184 & Inorganic pyrophosphatase (Ppa), MG351 & - & - & - \\
\hline 410 & 430 & A05_orf337 & $\begin{array}{l}\text { Glyceraldehyde-3-phosphate dehydrogenase (Gap), } \\
\text { MG301 }\end{array}$ & - & - & - \\
\hline 412 & 428 & A05_orf320 & Phosphotransacetylase (Pta), MG299 & - & - & - \\
\hline 446 & 393 & F11_orf358a & Pyruvate dehydrogenase E1 $\alpha$-subunit (PdhA), MG274 & - & - & - \\
\hline 447 & 392 & F11_orf327 & Pyruvate dehydrogenase E1 $\beta$-subunit (PdhB), MG273 & 2 & - & - \\
\hline 450 & 389 & F11_orf339 & Lipoate protein ligase (LplA), MG270 & - & - & - \\
\hline 516 & 321 & F10_orf160 & Dihydrofolate reductase (DhfR), MG228 & - & - & - \\
\hline 587 & 246 & K04_orf239 & 5'Guanylate kinase (Gmk), MG107 & 1 & - & - \\
\hline \multicolumn{7}{|c|}{ Lipoproteins } \\
\hline 102 & 052 & D09_orf657 & Putative lipoprotein, MG040 & 2 & - & + \\
\hline 384 & 456 & H08_orf1005 & Putative lipoprotein, MG321 & 3 & - & + \\
\hline 396 & 444 & H08_orf1325 & Putative lipoprotein, MG309 & 1 & - & - \\
\hline 431 & 408 & F11_orf760 & Putative lipoprotein, MG260 & 2 & - & - \\
\hline 548 & 288 & A65_orf7870 & Putative lipoprotein, MG260 & 2 & - & + \\
\hline 552 & 284 & A65_orf794 & Putative lipoprotein, MG260 & 1 & - & - \\
\hline \multicolumn{7}{|c|}{ Translation/transcription } \\
\hline 177 & 665 & K05_orf394 & Elongation factor Tu (Tuf), MG451 & - & - & - \\
\hline 303 & 539 & G12_orf122 & Ribosomal protein L7/L12, MG392 & 1 & - & - \\
\hline 438 & 401 & F11_orf160 & Transcription elongation factor (GreA), MG282 & - & - & - \\
\hline 506 & 331 & F10_orf444 & Trigger factor (Tig), MG238 & - & - & - \\
\hline 605 & 227 & G07_orf688 & Elongation factor G (Fus), MG89 & - & - & - \\
\hline \multicolumn{7}{|c|}{ Heat shock, chaperones } \\
\hline 269 & 573 & D02_orf543 & Heat-shock protein GroEL, MG392 & - & - & - \\
\hline 406 & 434 & A05_orf595 & Heat-shock protein DnaK, MG305 & - & $-/ \mathrm{LZ}$ & - \\
\hline \multicolumn{7}{|c|}{ Proposed structural and cytadherance-associated proteins } \\
\hline 388 & 452 & H08_orf672 & Cytadherence accessory protein (HMW3), MG317 & - & - & + \\
\hline 528 & 309 & F10_orf405 & Protein P65, MG217 & - & + & + \\
\hline $13 \|$ & 142 & E07_orf1218 & Protein P40 and P90, cleavage products, MG192 & 4 & - & - \\
\hline $14 \|$ & 141 & E07_orf1627 & Adhesin P1, MG191 & 5 & - & + \\
\hline $275 \|$ & 567 & D02_orf1036 & Protein P200, MG386 & - & - & - \\
\hline $393 \|$ & 447 & H08_orf1018 & Cytadherence accessory protein (HMW1), MG312 & - & + & + \\
\hline $527 \|$ & 310 & F10_orf1818 & Cytadherence accessory protein (HMW2), MG218 & - & $+/ \mathrm{LZ}$ & + \\
\hline \multicolumn{7}{|c|}{ Other functions } \\
\hline 154 & 688 & K05_orf270 & PasA family & 1 & - & - \\
\hline 174 & 668 & K05_orf140 & Osmotically inducible protein (OsmC), MG454 & - & - & - \\
\hline $520 \|$ & 317 & F10_orf380 & Cell division protein (FtsZ), MG224 & - & - & - \\
\hline 571 & 263 & A65_orf102 & Thioredoxin (Trx), MG124 & - & - & - \\
\hline \multicolumn{7}{|c|}{ Unknown functions } \\
\hline 217 & 625 & C12_orf141 & Osmotic inducible protein-C-like family, MG427 & 1 & - & - \\
\hline 251 & 591 & D02_orf353 & MG068 & - & - & - \\
\hline 350 & 491 & P02_orf474 & MP-specific membrane nuclease & 1 & - & - \\
\hline 366 & 474 & P01_orf1033 & MG328 & - & $+/ \mathrm{LZ}$ & + \\
\hline 439 & 400 & F11_orf582 & MG281 & - & - & - \\
\hline 451 & 387 & F11_orf358b & MG269 & - & + & - \\
\hline 461 & 376 & A19_orf1140 & MP-specific & 2 & - & - \\
\hline
\end{tabular}


Table 1 (cont.)

\begin{tabular}{|c|c|c|c|c|c|c|}
\hline \multirow[t]{2}{*}{ Gene no.* } & \multirow[t]{2}{*}{ MPN no† } & \multirow[t]{2}{*}{ ORF name $\neq$} & \multirow{2}{*}{$\begin{array}{l}\text { Proposed function/annotation (gene name) } \\
\text { and orthologous gene in } M . \text { genitalium (MG) }\end{array}$} & \multicolumn{3}{|c|}{ Structural features $\mathbb{S}$} \\
\hline & & & & TM & C-C & PR \\
\hline 514 & 323 & F10_orf153 & Probably Nrd1, MG230 & - & - & - \\
\hline 523 & 314 & F10_orf141B & Hypothetical protein (YabB) homologue, MG221 & - & - & - \\
\hline 540 & 297 & H10_orf149 & MG211 & - & + & - \\
\hline 541 & 295 & H10_orf220L & MP-specific & - & - & - \\
\hline
\end{tabular}

*Gene number according to the original publication by Himmelreich et al. (1996).

† MPN number according to the re-annotation by Dandekar et al. (2000).

$\ddagger$ ORF name according to the original publication by Himmelreich et al. (1996).

\TM, predicted transmembrane segment; C-C, predicted coiled-coil structure; PR, peptide repeat (4-10 aa in most instances); LZ, leucine zipper.

\| Seen after SDS-PAGE and Western blot.

and 2-D gels was done as described by Proft \& Herrmann (1994).

Nomenclature. All ORFs and proteins were named according to the numbers given in the original publication of the genome sequence (Himmelreich et al., 1996). With the re-annotation of the genome sequence of M. pneumoniae, the old nomenclature was replaced by a new one consisting of the prefix 'MPN' and a new number (Dandekar et al., 2000). This new nomenclature is presented together with the old one in Table 1. Additional information is available from the following websites: www.zmbh.de/M_pneumoniae and www.bork.EMBL-Heidelberg.DE/Annot/MP.

\section{RESULTS}

The experimental approach for the identification of the components of the Triton X-100 insoluble fraction of M. pneumoniae was as follows. The insoluble fraction was enriched by a method adapted from a procedure for the isolation of eukaryotic cytoskeletons (Herrmann \& Wiche, 1983). The individual proteins were separated by 2-D gel electrophoresis using immobilized $\mathrm{pH}$ gradients (IPGs) for the isoelectric focusing of proteins in the first dimension and SDS-PAGE for separation according to molecular mass in the second dimension. After staining with colloidal Coomassie blue, the protein spots were excised and analysed by MS as previously described in detail (Regula et al., 2000).

\section{Preparation of the Triton X-100 insoluble fraction}

Several slightly different procedures have been developed to remove the membranes and the cytosol from $M$. pneumoniae cells. The procedures vary mainly in the Triton X-100 and the salt concentrations, the temperature and the duration of the exposure of the bacteria to the detergent (Meng \& Pfister, 1980; Proft et al., 1995; Stevens \& Krause, 1991). We adapted a two-step procedure for the preparation of eukaryotic cytoskeletons (Herrmann \& Wiche, 1983) for two reasons. Firstly, eukaryotic cytoskeletons are well characterized and the structural components of M. pneumoniae are assumed to show similar properties to the components of eukaryotic cytoskeletons (Göbel et al., 1981; Meng \& Pfister, 1980; Neimark, 1977). Secondly, the extraction of M. pneumoniae cells with Triton X-100 while still adhering to a solid surface was most similar to methods used for electron microscopical analysis, where $M$. pneumoniae are treated and analysed on grids. In our procedure the bacteria were first exposed to a low Triton X-100 (0.2\%) and salt concentration (Fig. 1, fractions $\mathrm{P} 2$ and S3), and then in a second step the concentration was increased to $1 \%$ Triton X-100 and $1 \mathrm{M} \mathrm{NaCl}$ to give the fractions P4 and S5. Since the P4 fraction was exposed to the highest Triton X-100 concentration we called this fraction the Triton X-100 insoluble fraction and used it for all the experiments described. To check our extraction protocol, we examined the distribution of several proteins (HMW1, HMW2, HMW3, P65 and P200) which have been found almost exclusively in the Triton X-100 insoluble fraction after extraction of cells with 2\% Triton X-100 (Krause et al., 1997; Ogle et al., 1991; Proft \& Herrmann, 1994; Proft et al., 1995, 1996; Stevens \& Krause, 1991). Our method achieved the same distribution, with all these proteins concentrated in pellets $\mathrm{P} 2$ and P4 (data not shown). For further characterization, we examined the distribution of the proteins P1 (Kahane et al., 1985), P40, P90 (Proft \& Herrmann, 1994; Sperker et al., 1991), FtsZ and DnaK among the four fractions and, in accordance with published results, found the proteins P1, P40 and P90 in all the subcellular fractions (P2, P4, S3, S5) (Fig. 2). The proteins DnaK and FtsZ, the subcellular distribution of which has not been reported before, were also present in all subfractions (data not shown).

\section{Electron microscopic analysis of the Triton X-100 insoluble fraction}

Since our method to prepare the Triton X-100 insoluble fraction of M. pneumoniae was not exactly the same as those used by others in previous studies (Göbel et al., 1981; Meng \& Pfister, 1980; Krause, 1996; Stevens \& 
(a)

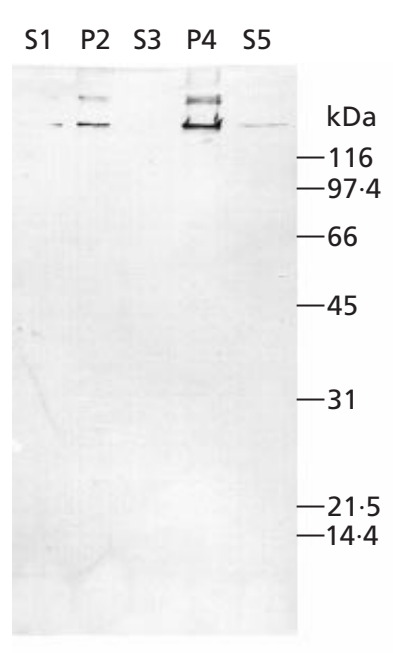

(b)

$\begin{array}{lllll}\text { S1 } & \text { P2 } & \text { S3 } & \text { P4 } & \text { S5 }\end{array}$

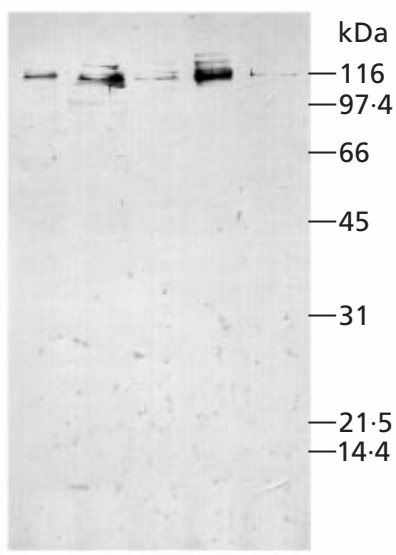

(c)

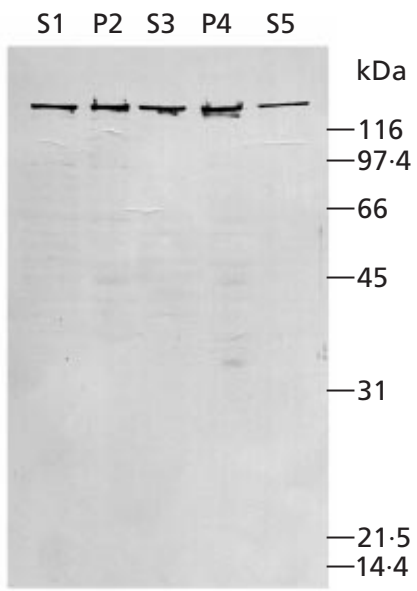

(d)

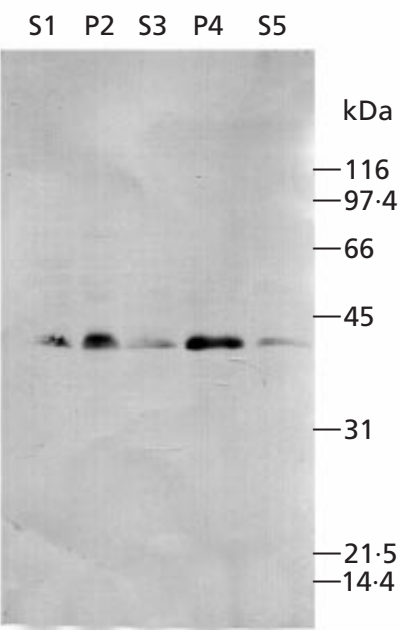

(e)

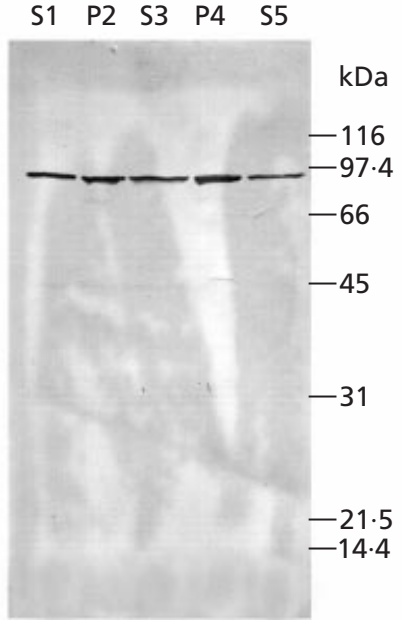

Fig. 2. SDS-polyacrylamide gels $(10 \%)$ and Western blots with monospecific antisera (Proft \& Herrmann, 1994). Fractions S1, S3, S5, P2 and P4 (see Fig. 1) were examined for proteins HMW1 (a), HMW3 (b), P1 (c), P40 (d) and P90 (e). P40 and P90 are the products of the ORF6 gene (Sperker et al., 1991). From each fraction, $5 \mu \mathrm{g}$ protein was applied per lane. The monospecific rabbit antisera were diluted between 1:1000 and 1:3000. As second antibody, an alkaline-phosphataseconjugated goat anti-rabbit antiserum diluted 1:10000 was used. Bound phosphatase-conjugated antibodies were detected using $70 \mu \mathrm{g}$ nitro blue tetrazolium chloride $\mathrm{ml}^{-1}$ and $35 \mu \mathrm{g}$ 5-bromo-4-chloro-3-indolyl phosphate $\mathrm{ml}^{-1}$ in alkaline phosphatase buffer.

Krause, 1991; Proft et al., 1995), we compared our results with those obtained when we prepared the Triton X-100 insoluble fraction according to Stevens \& Krause (1991). These authors used a higher Triton X-100 concentration $(2 \%)$, a lower salt concentration $(150 \mathrm{mM} \mathrm{NaCl})$ and incubation at $37^{\circ} \mathrm{C}$ for $30 \mathrm{~min}$. The two preparations appeared indistinguishable by electron microscopical inspection (Figs 3 and 4). We observed rather compact aggregates with a background of smaller material and only very rarely thin fibrous structures. These compact aggregates in the Triton X-100 insoluble fraction of M. pneumoniae were about $300 \mathrm{~nm}$ long and $80 \mathrm{~nm}$ thick, with a pattern of parallel stripes oriented perpendicular to their long axes (Fig. 3). Occasionally, appendages could be seen which appeared to resemble remnants of the cytoplasmic membrane. A similar structure could be seen in ultrathin cryosections of the attachment organelle from M. pneumoniae. One end of it seemed to be connected to the cytoplasmic membrane (Fig. 5). The structures showed all the features that have been described previously (Göbel et al., 1981; Meng \& Pfister, 1980).

\section{2-D gel electrophoresis}

In our study, using analytical 2-D gels with an IPG from 3-12 and with sensitive silver staining methods, we visualized about 100 proteins in the Triton X-100 

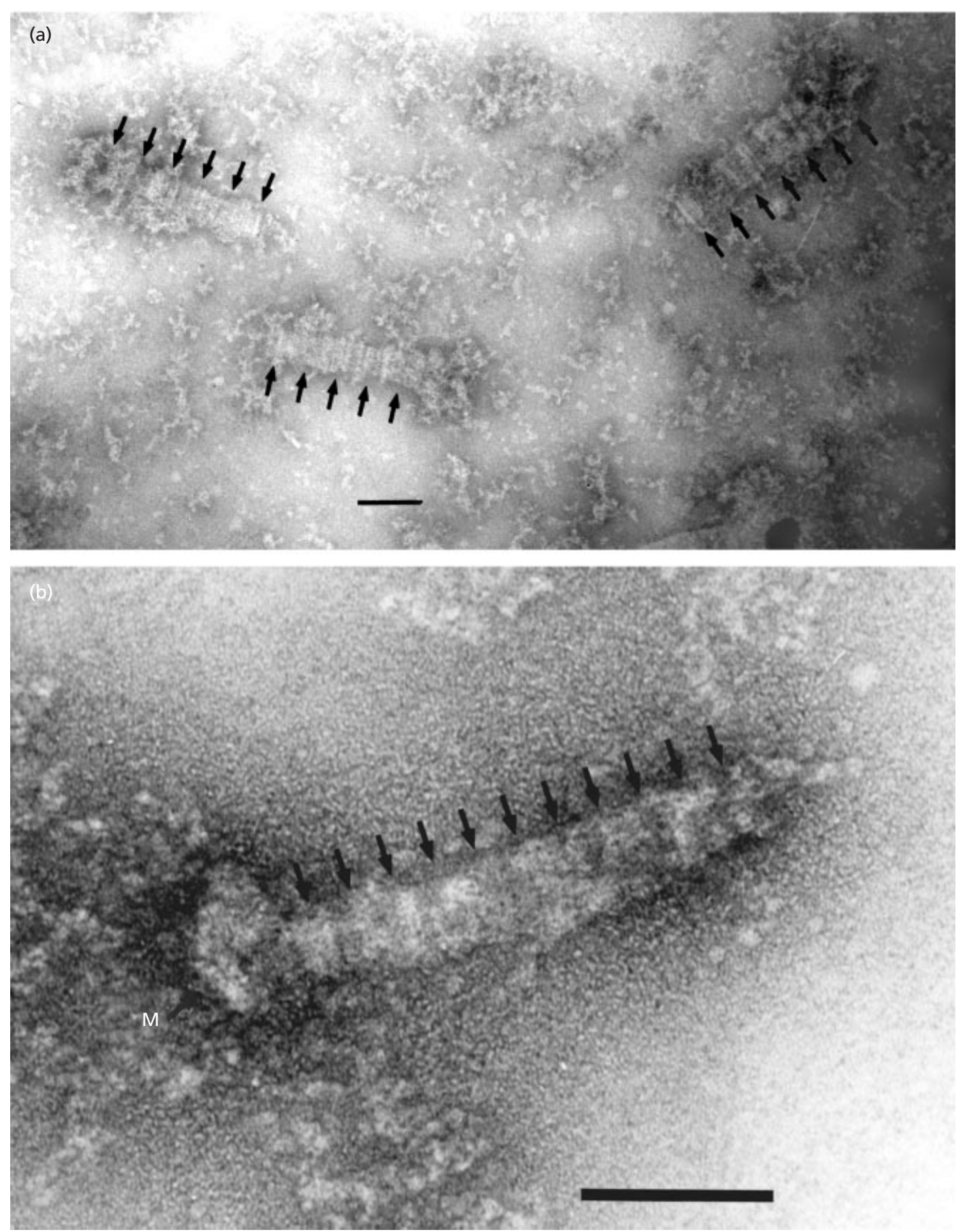

Fig. 3. Negatively stained sample of Triton $X-100$ resistant structures of $M$. pneumoniae. Examples of compact aggregates with striped structures (see also Fig. 5) are shown as found in the Triton X-100 insoluble fraction. Preparation was as described in Methods. Repeating features of the structure are indicated by arrows and the remains of the cytoplasmic membrane are indicated by a letter M. (a) Overview; (b) enlargement. Bars, $100 \mathrm{~nm}$.

insoluble fraction (Fig. 6). However, proteins stained with silver according to the classical method of Blum et al. (1987) were often poorly digested in the gel and only a few peptides were obtained, impeding protein identification by MS. Therefore, all 2-D gels that were used for MS were stained with colloidal Coomassie blue, en- abling about 50 proteins to be visualized in a preparative 2-D gel of the Triton X-100 insoluble fraction (Fig. 7). This method was not as sensitive as silver staining, but was better than the conventional Coomassie blue staining technique. Since 2-D gels covering narrow IPGs (Görg et al., 1997) between 10 and 12 were difficult to 


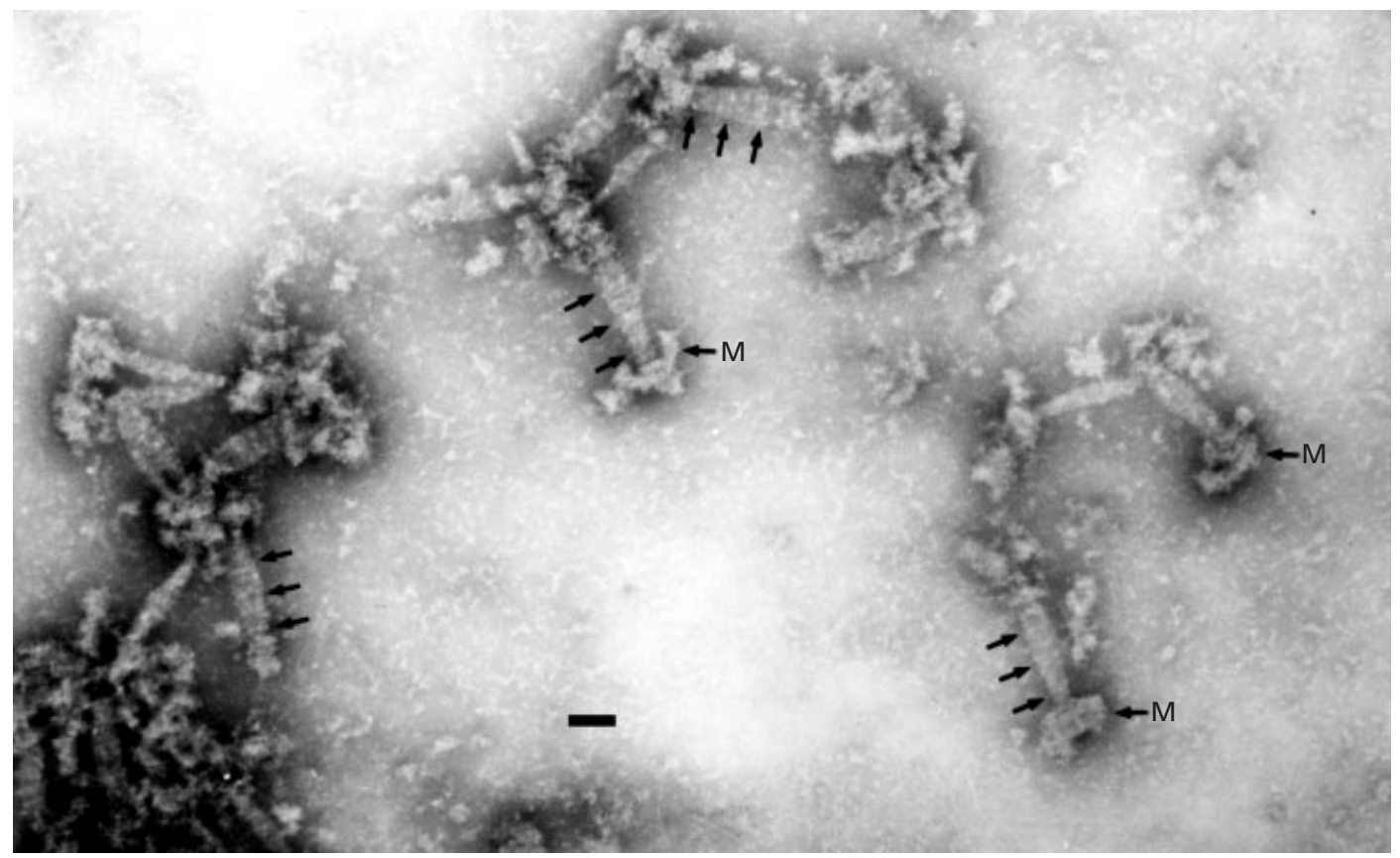

Fig. 4. Negatively stained sample of compact aggregates found in the Triton X-100 insoluble fraction of M. pneumoniae. Preparations were done according to Stevens \& Krause (1991). Repeating rings in the striped structure are indicated by groups of arrows. Membrane fragments (M) are occasionally still connected to the striped structure. Bar, $100 \mathrm{~nm}$.

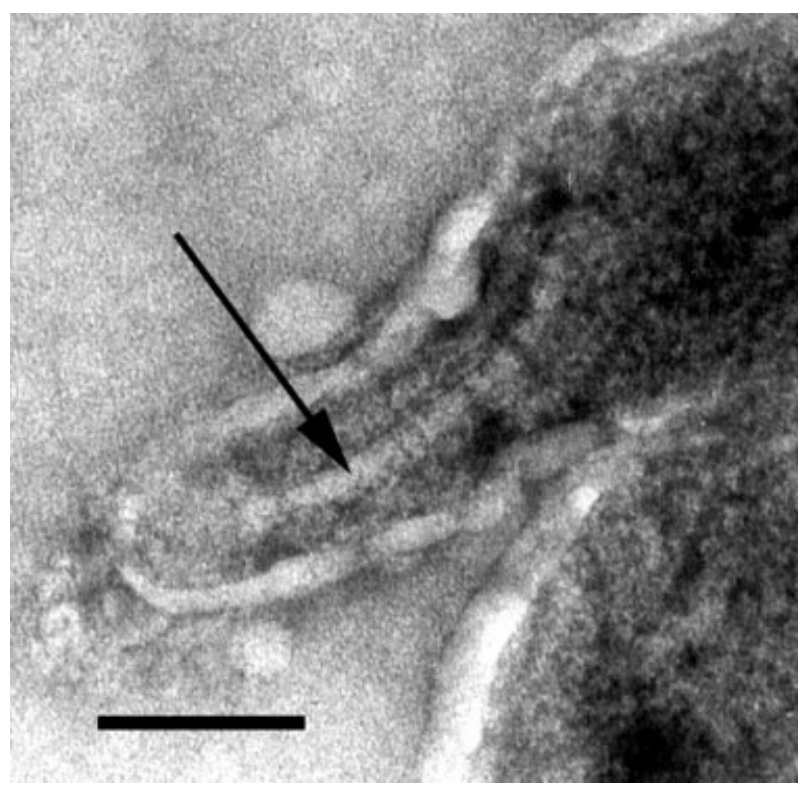

Fig. 5. Ultrathin cryosection of $M$. pneumoniae. The arrow marks a structure in the attachment organelle, which is striped perpendicular to its long axis. The dimension is similar to the tip structures (compact aggregates) in Figs 3 and 4. Bar, $100 \mathrm{~nm}$.

handle, IPGs from 4-9 or 3-10 and, more recently, 3-12 were used for most of the analyses of the composition of the Triton X-100 insoluble fraction. As shown in Fig. 6, the Triton X-100 insoluble fraction contains a number of basic proteins, which have not yet been identified.
Their role and participation in the formation of the structures seen in Fig. 3 and 4 remain to be analysed.

For comparison and demonstration of the enrichment of certain proteins in the Triton X-100 insoluble fraction, it should be mentioned that about 225 proteins were visible after staining of 2-D gels of complete cell extracts with colloidal Coomassie blue, and about 450 proteins after staining with silver according to the method of Blum et al. (1987) (Regula et al., 2000).

\section{Components of the Triton X-100 insoluble fraction}

All 50 proteins visible after separation of the Triton X100 insoluble fraction in a 2-D gel system with an IPG from 3 to 10 and staining with colloidal Coomassie blue (Fig. 7) were analysed by MS. The characteristics of the 41 proteins that were identified and assigned are summarized in Table 1 . We also included those proteins that could be assigned to the Triton X-100 insoluble fraction by 1-D SDS-PAGE and Western blotting (data not shown) or MS, but which were not identified by 2-D gel electrophoresis (Table 1) and MS.

The positions of 31 proteins in the 2-D gels were consistent with the predicted molecular masses and the pIs of the corresponding ORFs of M. pneumoniae. Two proteins, P65 (528, F10_orf405) and HMW3 (388, H08 orf672), migrated slower than predicted, as established previously (Ogle et al., 1991; Proft et al., 1995). Nine proteins were detected in faster migrating spots than predicted from their calculated ORF size. This was not due to an abnormal migration of these proteins in the 

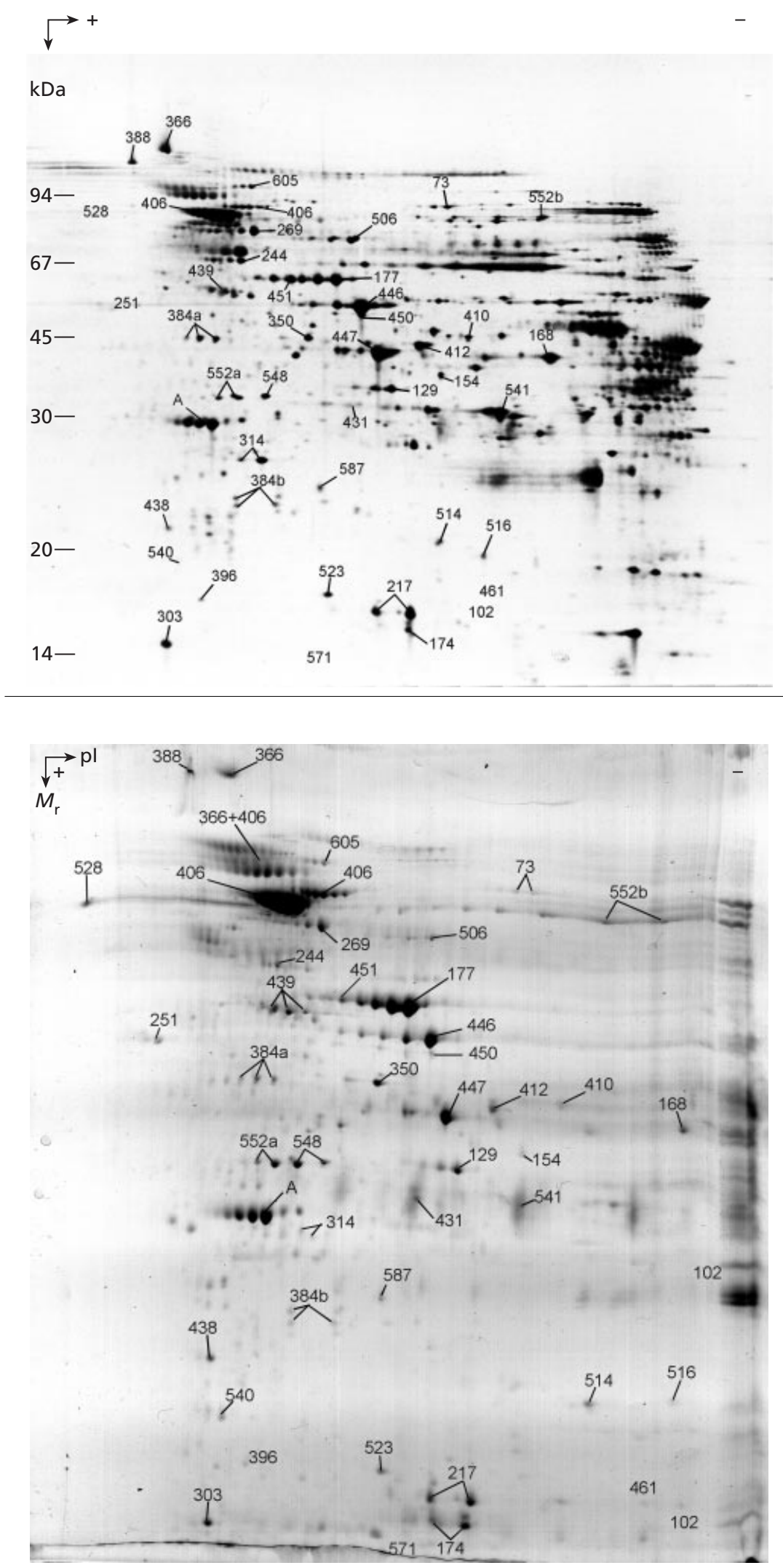

Fig. 6. Analytical 2-D gel with an immobilized $\mathrm{pH}$ gradient from 3 to 12 and a horizontal SDS-polyacrylamide gel (13\%). The Triton X-100 insoluble fraction (P4) was separated by 2-D gel electrophoresis and the proteins were silver-stained. The assignment of the proteins to the ORF numbers (Himmelreich et al., 1996) was based on results from a Coomassie-blue-stained gel (Fig. 7). The protein labelled 'A' could not be correlated with any $M$. pneumoniae ORF.

Fig. 7. Preparative 2-D gel of the Triton $\mathrm{X}-100$ insoluble fraction. About $400 \mu \mathrm{g}$ protein of fraction P4 were separated on an immobilized $\mathrm{pH}$ gradient from 3 to 10 and a vertical SDS-polyacrylamide gel $(12.5 \%)$ in the second dimension. The gel was stained with colloidal Coomassie blue and used for protein analysis by MS.

gel, but rather because these proteins were cleavage products of either in vivo post-translational processing or, less probably, in vitro artefacts of sample prep- aration. By analysing the distribution of the peptides identified by MS, it was possible to determine approximately the ends of the cleaved proteins and their 
presumptive molecular masses and pIs (for details, see Regula et al., 2000).

Six of the nine truncated proteins were derived from lipoproteins of the murein lipoprotein type of Escherichia coli. The other three proteins had one or more transmembrane domains. Among the strongly stained proteins, only one could not be assigned to an ORF from M. pneumoniae, (spot A in Figs 6 and 7). This protein is probably the apolipoprotein A1 precursor, a serum component which probably has an affinity for the surface of M. pneumoniae (Regula et al., 2000). To analyse the effect of temperature and duration of exposure on the protein pattern of Triton X-100 fractionation, we incubated the adherent cell fragments (Fig. 1) with the same buffers for $30 \mathrm{~min}$ at $37^{\circ} \mathrm{C}$ with mild agitation. Under these conditions, the main components of the Triton X-100 insoluble fraction, such as DnaK (406), EF-Tu (177), PdhA (446) and PdhB (447) remained the most prevalent components, but some additional proteins were enriched. These proteins were ribonucleotide reductase 2 (F10_orf339, 515), DNAdirected RNA polymerase subunit $\alpha$, RpoA (GT9_orf 327, 641), phenylalanine tRNA ligase (C09_orf341, 50) and UDP-glucose isomerase, GalE (A65_orf338, 577) (data not shown).

\section{DISCUSSION}

The rationale for analysing the Triton X-100 insoluble fraction of M. pneumoniae was the observation that $M$. pneumoniae has fibre-like structures as seen by electron microscopy (Biberfeld \& Biberfeld, 1970; Meng \& Pfister, 1980) and that similar structures persist after treatment of M. pneumoniae with the detergent Triton X-100 (Göbel et al., 1981; Meng \& Pfister, 1980; Stevens \& Krause, 1991). However, it should be stressed that the conception of a cytoskeleton-like structure in M. pneumoniae is rather vague, and so far nobody has been able to correlate defined proteins with the observed fibre-like structures directly. Although our procedure varied somewhat compared to previously described methods, the compact structures (Figs 3 and 4) observed in our preparation seemed to be very similar to those described previously as tip structures; therefore we assume they are identical. However, only occasionally and not reproducibly did we see thin fibrous structures with a diameter of only $6-7 \mathrm{~nm}$. Since the main differences between our method and those of others were the higher salt concentrations and lower incubation temperature, it might be that under these conditions these thin fibres are unstable. The Triton X-100 insoluble preparation contained large amounts of smaller structures (Figs 3 and 4), which could be precursor or degradation products of the tip structure. This high background excludes correlation of specific proteins from the total composition of the Triton X-100 insoluble fraction with the tip structure. Comparison of the tip structure (Fig. 3) with thin sections of complete M. pneumoniae cells (Fig. 5), suggests that they are the same structure, but this needs to be proven by direct methods such as immunoelectron microscopy. It is not known exactly what renders a protein insoluble in Triton X-100 and it is not yet possible to predict this feature from its primary sequence. Any modification of a given protocol for a Triton X-100 fractionation may influence the solubility of individual proteins, as was shown by changing temperature and duration of exposure. We assume this is related to incomplete removal of residual membrane fragments, which may influence the separation of proteins in the first dimension of 2-D gel electrophoresis. For some proteins, the formation of 'membrane rafts' might be a possible explanation. 'Rafts' are sphingolipid-cholesterol complexes, proposed to function as platforms for the attachment of proteins in the fluid lipid bilayer. These complexes are insoluble in Triton X-100, but the proteins, once separated from the rafts, are soluble (Simons \& Ikonen, 1997). Experimental data proving the existence of rafts in M. pneumoniae are not available. Although sphingolipids are only present in minor amounts in membranes of $M$. pneumoniae when grown in serum-containing media, the formation of rafts seems possible since these bacteria have the biosynthetic capacity to synthesize sphingolipids if the right precursors are present (A. Wieslander, personal communication). One could screen for rafts by treating the bacteria with $\beta$-cyclodextrin to selectively deplete the membrane of cholesterol and determining whether some proteins from the Triton X-100 insoluble fraction then appear in the soluble fraction.

In an analytical 2-D protein gels (Fig. 3) of the Triton X100 insoluble fraction about 100 protein spots could be visualized by silver staining. After staining a preparative 2-D gel with colloidal Coomassie blue (Fig. 4) only about 50 protein spots were detected, of which 41 could be assigned to an M. pneumoniae ORF in the $M$. pneumoniae database.

To get as complete a picture as possible of the composition of the detergent-insoluble complex, we added seven proteins that did not appear in the 2-D gel analysis, but were clearly seen after 1-D SDS-PAGE and Western blotting (Table 1) or MS. These proteins had already been assigned to the Triton X-100 insoluble fraction in previously published studies (Kahane et al., 1985; Krause, 1996; Krause et al., 1982; Proft \& Herrmann, 1994; Proft et al., 1995, 1996).

In general, the method used cannot differentiate between proteins that might be structural components and those that interact with these structural components. The attachment organelle provides an example. Its formation depends on the proteins HMW1 (393), HMW2 (527) and HMW3 (388) (Krause, 1996), but it functions only as an adherence organelle if the proposed adhesin P1 (14) is properly inserted, together with the proteins P40 and P90 (Layh-Schmitt \& Herrmann, 1994; LayhSchmitt \& Harkenthal, 1999). Since it is not easy to differentiate between true adhesins (P1), proteins guiding the adhesin to its correct position (P40, P90) and proposed structural proteins of the attachment organelle, the term cytadherence accessory protein seems to be a useful generic term (Krause, 1996). These accessory proteins are presently defined by mutations in genes that 
result in a cytadherence-negative phenotype (failure to bind to human erythrocytes). Erythrocytes are convenient model cells because they carry receptors for $M$. pneumoniae, even though M. pneumoniae is not normally found in the bloodstream. The examination of cytadherence-negative mutants has confirmed the roles of all the proteins listed in Table 1 under 'Proposed structural and cytadherence associated proteins' with the exception of P65 (Proft et al., 1995) and P200 (Proft et al., 1996). These two proteins are listed here because they share characteristics with HMW1 and HMW3, including an extended proline-rich acidic domain and significantly slower migration in SDS-PAGE gels than might be expected from their predicted primary sequence.

Based on predicted protein structures, the proteins P01 orf1033 (366), H10_orf149 (540) and F11_orf358b (451) appear to be promising new candidates for the functional group of proposed structural proteins (Table 1, unknown function). P01_orf1033 (873 aa) and F11 orf358b (347 aa) share sequence identity of about $25 \%$ over almost their entire length with HMW2, and they are predicted to have extended coiled-coil structures (Lupas, 1996) like HMW2. In addition, HMW2 and P01_orf1033 (366) contain several leucine zipper motifs. These are known to enable dimerization in DNAbinding proteins, but so far the interaction of the proteins P01_orf1033 and HMW2 with DNA has not been studied. Whether these leucine zipper motifs really contribute to the formation of specific structures remains to be analysed.

Other potential candidates for the formation of a cytoskeleton-like structure might be found among the lipoproteins because they could form a connection between the membrane and a possible protein network beneath it. However, none of the lipoproteins identified was a full-length product of the corresponding ORF. Their size and pI, and the restricted distribution of characterized peptides for each lipoprotein, showed clearly that they were cleavage products.

As a supportive method for the assignment as a cytadherence-associated protein, the distribution of proteins in a subcellular fraction can be monitored by SDS-PAGE and Western blotting, but this approach requires many monospecific antibodies. The analysis of a few selected proteins by this method showed that the proteins HMW1 (393), HMW2 (527), HMW3 (388), P65 (528) and P200 (275) were present almost exclusively in fractions P4 and P2 (Figs 1 and 2). The proteins P1 (14), P40 (13), P90 (13), FtsZ (520) and DnaK (406) were distributed in all fractions (data not shown). This could indicate that the proteins of the second group are less firmly bound, or have a variety of modifications with different affinities for specific binding partners. In vivo cross-linking experiments seem to be another promising method for searching for cytadherence-associated proteins. Using this approach, several proteins have been identified that interact directly or indirectly with the P1 adhesin (Layh-Schmitt \& Herrmann, 1994; Layh-
Schmitt et al., 2000). Besides some of the known cytadherence-associated proteins, DnaK (406) and the E1 $\alpha$-subunit of pyruvate dehydrogenase (446) were components of proteins complexes that were enriched by using antibodies against the P1 adhesin (Layh-Schmitt et al., 2000).

It seems unlikely that proteins assigned functionally as enzymes in energy metabolism are involved in the formation of a cytoskeleton-like structure. In this context, the proposal of Norris et al. (1996) should be considered. They suggested that the enzymes involved in a specific metabolic pathway are organized in larger protein complexes, which might assemble with other complexes into large coherent structures inside the cell, forming the proposed 'enzoskeleton' (Norris et al., 1996). The situation seems different with the two most abundant proteins of the fraction, DnaK and elongation factor Tu. Both proteins have the potential to polymerize. DnaK has leucine zipper motifs and it has been shown that the elongation factor $\mathrm{Tu}$ polymerizes into filaments under appropriate conditions in vitro (Beck et al., 1978). Therefore, we cannot exclude the possibility that DnaK or elongation factor $\mathrm{Tu}$ are components of the fibrous structures seen by electron microscopy (Göbel et al., 1981; Meng \& Pfister, 1980). In summary, it now seems feasible to isolate at least the tip structure devoid of the smaller contaminating material and then to determine its structural components by MS. Based on this information, the synthesis of monospecific antibodies to all the potential components is then feasible and these can then be used to study the organization of the tip structure by immunocytochemistry.

\section{ACKNOWLEDGEMENTS}

We thank D. Hofmann for Western blotting experiments, B. Ueberle for providing unpublished data, A. Bosserhoff and E. Pirkl for skillful technical assistance, J. Weiss and coworkers for the preparation of antisera, H. Herrmann-Lerdon for introducing us to Triton X-100 fractionation, I. Schmid for secretarial work, H. U. Schairer for a generous gift of equipment and H. W. Zentgraf for advice on electron microscopy. Last but not least, we appreciate the valuable contributions of the late I. Kahane in the early stages of this work. The research was supported by grants from the Deutsche Forschungsgemeinschaft (He 780/10-1, 13-1) and by the Fonds der Chemischen Industrie.

\section{REFERENCES}

Beck, B. D., Arscott, P. G. \& Jacobson, A. (1978). Novel properties of bacterial elongation factor Tu. Proc Natl Acad Sci US A 75, 1250-1254.

Biberfeld, G. \& Biberfeld, P. (1970). Ultrastructural features of Mycoplasma pneumoniae. J Bacteriol 102, 855-861.

Blum, H., Beiers, H. \& Gross, H. J. (1987). Improved silver staining of plant proteins, RNA and DNA in polyacrylamide gels. Electrophoresis 8, 93-99.

Dallo, S. F., Chavoya, A. \& Baseman, J. B. (1990). Characterization of the gene for a 30-kilodalton adhesion-related protein of Mycoplasma pneumoniae. Infect Immun 58, 4163-4165. 
Dandekar, T., Huynen, M., Regula, J. T. \& 10 other authors (2000). Re-annotating the Mycoplasma pneumoniae genome sequence: adding value, function and reading frames. Nucleic Acids Res 28, 3278-3288.

Dirksen, L. B., Proft, T., Hilbert, H., Plagens, H., Herrmann, R. \& Krause, D. C. (1996). Sequence analysis and characterization of the hmw gene cluster of Mycoplasma pneumoniae. Gene 171, 19-25.

Eng, J. K., McCormack, A. L. \& Yates, J. R. I. (1994). An approach to correlate tandem mass spectral data of peptides with amino acid sequences in a protein database. J Am Soc Mass Spectrom 5, 976-989.

Fountoulakis, M., Takács, B. \& Langen, H. (1998). Two-dimensional map of basic proteins of Haemophilus influenzae. Electrophoresis 19, 761-766.

Göbel, U., Speth, V. \& Bredt, W. (1981). Filamentous structures in adherent Mycoplasma pneumoniae cells treated with nonionic detergents. J Cell Biol 91, 537-543.

Görg, A., Postel, W. \& Günther, S. (1988). The current state of two-dimensional electrophoresis with immobilized $\mathrm{pH}$ gradients. Electrophoresis 9, 531-546.

Görg, A., Obermaier, C., Boguth, G., Csordas, A., Diaz, J. J. \& Madjar, J. J. (1997). Very alkaline immobilized $\mathrm{pH}$ gradients for two-dimensional electrophoresis of ribosomal and nuclear proteins. Electrophoresis 18, 328-337.

Görg, A., Boguth, G., Obermaier, C. \& Weiss, W. (1998). Twodimensional electrophoresis of proteins in an immobilized $\mathrm{pH}$ 4-12 gradient. Electrophoresis 19, 1516-1519.

Görg, A., Obermaier, C., Boguth, G. \& Weiss, W. (1999). Recent developments in two-dimensional gel electrophoresis with immobilized $\mathrm{pH}$ gradients: wide gradients up to $\mathrm{pH} 12$, longer separation distances and simplified procedures. Electrophoresis 20, 712-717.

Griffiths, G., McDowall, A. F., Back, R. \& Dubochet, J. (1984). On the preparation of cryosections for immunocytochemistry. $J$ Ultrastruct Res 89, 65-78.

Herrmann, H. \& Wiche, G. (1983). Specific in situ phosphorylation of plectin in detergent-resistant cytoskeletons from cultured Chinese hamster ovary cells. J Biol Chem 258, 14610-14618.

Herrmann, R. \& Reiner, B. (1998). Mycoplasma pneumoniae and Mycoplasma genitalium: a comparison of two closely related bacterial species. Curr Opin Microbiol 1, 572-579.

Himmelreich, R., Hilbert, H., Plagens, H., Pirkl, E., Li, B. C. \& Herrmann, R. (1996). Complete sequence analysis of the genome of the bacterium Mycoplasma pneumoniae. Nucleic Acids Res 24, 4420-4449.

Himmelreich, R., Plagens, H., Hilbert, H., Reiner, B. \& Herrmann, R. (1997). Comparative analysis of the genomes of the bacteria Mycoplasma pneumoniae and Mycoplasma genitalium. Nucleic Acids Res 25, 701-712.

Hu, P. C., Collier, A. M. \& Baseman, J. B. (1977). Surface parasitism by Mycoplasma pneumoniae of respiratory epithelium. J Exp Med 145, 1328-1343.

Inamine, J. M., Loechel, S. \& Hu, P. C. (1988). Analysis of the nucleotide sequence of the P1 operon of Mycoplasma pneumoniae. Gene 73, 175-183.

Kahane, I., Tucker, S., Leith, D. K., Morrison Plummer, J. \& Baseman, J. B. (1985). Detection of the major adhesin P1 in triton shells of virulent Mycoplasma pneumoniae. Infect Immun 50, 944-946.

Krause, D. C. (1996). Mycoplasma pneumoniae cytadherence: unravelling the tie that binds. Mol Microbiol 20, 247-253.
Krause, D. C., Leith, D. K., Wilson, R. M. \& Baseman, J. B. (1982). Identification of Mycoplasma pneumoniae proteins associated with hemadsorption and virulence. Infect Immun 35, 809-817.

Krause, D. C., Proft, T., Hedreyda, C. T., Hilbert, H., Plagens, H. \& Herrmann, R. (1997). Transposon mutagenesis reinforces the correlation between Mycoplasma pneumoniae cytoskeletal protein HMW2 and cytadherence. J Bacteriol 179, 2668-2677.

Layh-Schmitt, G. \& Harkenthal, M. (1999). The 40- and 90-kDa membrane proteins (ORF6 gene product) of Mycoplasma pneumoniae are responsible for the tip structure formation and P1 (adhesin) association with the Triton shell. FEMS Microbiol Lett 174, 143-149.

Layh-Schmitt, G. \& Herrmann, R. (1994). Spatial arrangement of gene products of the $\mathrm{P} 1$ operon in the membrane of Mycoplasma pneumoniae. Infect Immun 62, 974-979.

Layh-Schmitt, G., Hilbert, H. \& Pirkl, E. (1995). A spontaneous hemadsorption-negative mutant of Mycoplasma pneumoniae exhibits a truncated adhesin-related 30-kilodalton protein and lacks the cytadherence-accessory protein HMW1. J Bacteriol 177, 843-846.

Layh-Schmitt, G., Podtelejnikov, A. \& Mann, M. (2000). Proteins complexed to the P1 adhesin of Mycoplasma pneumoniae. Microbiology 146, 741-747.

Lupas, A. (1996). Coiled coils: new structures and new functions. Trends Biochem Sci 21, 375-382.

Meng, K. E. \& Pfister, R. M. (1980). Intracellular structures of Mycoplasma pneumoniae revealed after membrane removal. J Bacteriol 144, 390-399.

Neimark, H. C. (1977). Extraction of an actin-like protein from the prokaryote Mycoplasma pneumoniae. Proc Natl Acad Sci US A 74, 4041-4045.

Norris, V., Turnock, G. \& Sigee, D. (1996). The Escherichia coli enzoskeleton. Mol Microbiol 19, 197-204.

Ogle, K. F., Lee, K. K. \& Krause, D. C. (1991). Cloning and analysis of the gene encoding the cytadherence phase-variable protein HMW3 from Mycoplasma pneumoniae. Gene 97, 69-75.

Pollack, J. D., Williams, M. V. \& McElhaney, R. N. (1997). The comparative metabolism of the mollicutes (Mycoplasmas): the utility for taxonomic classification and the relationship of putative gene annotation and phylogeny to enzymatic function in the smallest free-living cells. Crit Rev Microbiol 23, 269-354.

Proft, T. \& Herrmann, R. (1994). Identification and characterization of hitherto unknown Mycoplasma pneumoniae proteins. Mol Microbiol 13, 337-348.

Proft, T., Hilbert, H., Layh-Schmitt, G. \& Herrmann, R. (1995). The proline-rich P65 protein of Mycoplasma pneumoniae is a component of the Triton X-100-insoluble fraction and exhibits size polymorphism in the strains M129 and FH. J Bacteriol 177, 3370-3378.

Proft, T., Hilbert, H., Plagens, H. \& Herrmann, R. (1996). The P200 protein of Mycoplasma pneumoniae shows common features with the cytadherence-associated proteins HMW1 and HMW3. Gene 171, 79-82.

Radestock, U. \& Bredt, W. (1977). Motility of Mycoplasma pneumoniae. J Bacteriol 129, 1495-1501.

Razin, S. \& Jacobs, E. (1992). Mycoplasma adhesion. J Gen Microbiol 138, 407-422.

Razin, S., Yogev, D. \& Naot, Y. (1998). Molecular biology and pathogenicity of mycoplasmas. Microbiol Mol Biol Rev 62, 1094-1156.

Regula, J. T., Ueberle, B., Boguth, G., Görg, A., Schnölzer, M., 
Herrmann, R. \& Frank, R. (2000). Towards a proteome map of Mycoplasma pneumoniae. Electrophoresis 21, 3765-3780.

Romero-Arroyo, C. E., Jordan, J., Peacock, S. J., Willby, M. J., Farmer, M. A. \& Krause, D. C. (1999). Mycoplasma pneumoniae protein P30 is required for cytadherence and associated with proper cell development. J Bacteriol 181, 1079-1087.

Shevchenko, A., Jensen, O. N., Podtelejnikov, A. V. \& 7 other authors (1996). Linking genome and proteome by mass spectrometry: large-scale identification of yeast proteins from two dimensional gels. Proc Natl Acad Sci U S A 93, 14440-14445.

Simons, K. \& Ikonen, E. (1997). Functional rafts in cell membranes. Nature 387, 569-572.

Sperker, B., Hu, P. \& Herrmann, R. (1991). Identification of gene products of the P1 operon of Mycoplasma pneumoniae. Mol Microbiol 5, 299-306.

Starger, J. M. \& Goldman, R. D. (1977). Isolation and preliminary characterization of $10-\mathrm{nm}$ filaments from baby hamster kidney (BHK-21) cells. Proc Natl Acad Sci U S A 74, 2422-2426.

Steinert, P. M., Zimmerman, S. B., Starger, J. M. \& Goldman, R. D. (1978). Ten-nanometer filaments of hamster BHK-21 cells and epidermal keratin filaments have similar structures. Proc Natl Acad Sci US A 75, 6098-6101.

Stevens, M. K. \& Krause, D. C. (1991). Localization of the Mycoplasma pneumoniae cytadherence-accessory proteins HMW1 and HMW4 in the cytoskeletonlike Triton shell. $J$ Bacteriol 173, 1041-1050.

Stevens, M. K. \& Krause, D. C. (1992). Mycoplasma pneumoniae cytadherence phase-variable protein HMW3 is a component of the attachment organelle. J Bacteriol 174, 4265-4274.

Su, C. J., Tryon, V. V. \& Baseman, J. B. (1987). Cloning and sequence analysis of cytadhesin P1 gene from Mycoplasma pneumoniae. Infect Immun 55, 3023-3029.

Trachtenberg, S. (1998). Mollicutes - wall-less bacteria with internal cytoskeletons. J Struct Biol 124, 244-256.

Wasinger, V.C., Cordwell, S. J., Cerpa Poljak, A. \& 7 other authors (1995). Progress with gene-product mapping of the Mollicutes: Mycoplasma genitalium. Electrophoresis 16, 10901094

Wasinger, V. C., Pollack, J. D. \& Humphery-Smith, I. (2000). The proteome of Mycoplasma genitalium. Chaps-soluble component. Eur J Biochem 267, 1571-1582.

Weisburg, W. G., Tully, J. G., Rose, D. L. \& 9 other authors (1989). A phylogenetic analysis of the mycoplasmas: basis for their classification. J Bacteriol 171, 6455-6467.

Wilkins, M. R., Sanchez, J. C., Williams, K. L. \& Hochstrasser, D. F. (1996). Current challenges and future applications for protein maps and post-translational vector maps in proteome projects. Electrophoresis 17, 830-838.

Wilson, M. H. \& Collier, A. M. (1976). Ultrastructural study of Mycoplasma pneumoniae in organ culture. J Bacteriol 125, 332-339.

Received 25 September 2000; revised 8 December 2000; accepted 14 December 2000. 